\title{
A Case of Synovitis-acne-pustulosis-hyperostosis-osteitis Syndrome with Bilateral Pleural Effusion
}

\author{
Maho Adachi-Katayama ${ }^{1,2}$, Yuya Kondo ${ }^{1}$, Shota Okamoto ${ }^{1}$, Ryota Sato ${ }^{1}$, Satoshi Morinaka ${ }^{1}$, \\ Taihei Nishiyama ${ }^{1}$, Mayu Terasaki ${ }^{1}$, Toshihiko Terasaki ${ }^{1}$, Hirofumi Toko ${ }^{1}$, Mizuki Yagishita ${ }^{1}$, \\ Hiroyuki Takahashi ${ }^{1}$, Shinya Hagiwara ${ }^{1}$, Hiroto Tsuboi ${ }^{1}$, \\ Takayuki Sumida ${ }^{1}$ and Isao Matsumoto ${ }^{1}$
}

\begin{abstract}
:
Pleural effusion is a rare manifestation in synovitis-acne-pustulosis-hyperostosis-osteitis (SAPHO) syndrome, which is characterized by the presence of osteoarticular lesions and dermatological involvement. We herein report a 71-year-old man with pleural effusion resulting from SAPHO syndrome. He was successfully treated using corticosteroids and has experienced no recurrence for one year. We should consider SAPHO syndrome when encountering cases of anterior chest pain and pleural fluid.
\end{abstract}

Key words: SAPHO syndrome, pleural effusion, hypoxia, anterior chest pain

(Intern Med Advance Publication)

(DOI: 10.2169/internalmedicine.8473-21)

\section{Introduction}

Synovitis-acne-pustulosis-hyperostosis-osteitis (SAPHO) syndrome was first introduced by Chamot et al. in 1987 (1). It is characterized by the presence of osteoarticular and dermatological lesions. Because the syndrome is commonly under-recognized or misdiagnosed, the true incidence and prevalence of SAPHO syndrome are unknown (2), and the etiology, pathogenic mechanism, and target therapy of the disease are still unclear. A variety of manifestations are known to be associated with SAPHO syndrome; however, pleural involvement with this disease is a rare manifestation.

We herein report a case of SAPHO syndrome with bilateral pleural effusion.

\section{Case Report}

A 71-year-old man presented to our hospital with a 3month history of anterior chest pain and shortness of breath on exertion. He was an ex-smoker and had a 40-year complaint of lower back pain with morning stiffness. He had previously been diagnosed with palmoplantar pustulosis about 30 years earlier and taken topical medication for his skin lesions for several years. Five years before admission, he noticed anterior chest pain, but he did not have it examined. A medical checkup at a nearby clinic revealed hypoxia and bilateral pleural effusion. He was referred to our rheumatology clinic on suspicion of pleuritis-associated connective tissue disease and was admitted for a further investigation and treatment.

On admission, he was afebrile, and his blood pressure and pulse rate were normal. His respiratory rate was 18 , and his peripheral oxygen saturation was $98 \%$ on $2 \mathrm{~L} /$ minute of oxygen via nasal cannula. His bilateral sternoclavicular joints were thickened, and blisters were detected on the palms and soles. Laboratory data were as follows: white blood cell count $10,100 / \mu \mathrm{L}$, hemoglobin $10.5 \mathrm{~g} / \mathrm{dL}$, total protein (TP) $7.7 \mathrm{~g} / \mathrm{dL}$, albumin $2.6 \mathrm{~g} / \mathrm{dL}$, lactate dehydrogenase (LDH) $118 \mathrm{U} / \mathrm{L}, \mathrm{C}$-reactive protein $9.31 \mathrm{mg} / \mathrm{dL}$, erythrocyte sedimentation rate $54 \mathrm{~mm} / \mathrm{h}$, serum amyloid A 144.8 $\mu \mathrm{g} / \mathrm{mL}, \mathrm{IgG}$ 2,490 mg/dL, IgG4 $189 \mathrm{mg} / \mathrm{dL}$, rheumatoid factor $5 \mathrm{U} / \mathrm{mL}$, anti-cyclic citrullinated peptide (CCP) antibody $<0.5 \mathrm{U} / \mathrm{mL}$, and antinuclear antibody $80 \mathrm{x}$ (homogenous pat-

${ }^{1}$ Department of Internal Medicine, Faculty of Medicine, University of Tsukuba, Japan and ${ }^{2}$ Department of General Medicine, Mito Kyodo General Hospital, University of Tsukuba, Japan

Received: August 9, 2021; Accepted: December 10, 2021; Advance Publication by J-STAGE: February 8, 2022

Correspondence to Dr. Isao Matsumoto, ismatsu@md.tsukuba.ac.jp 


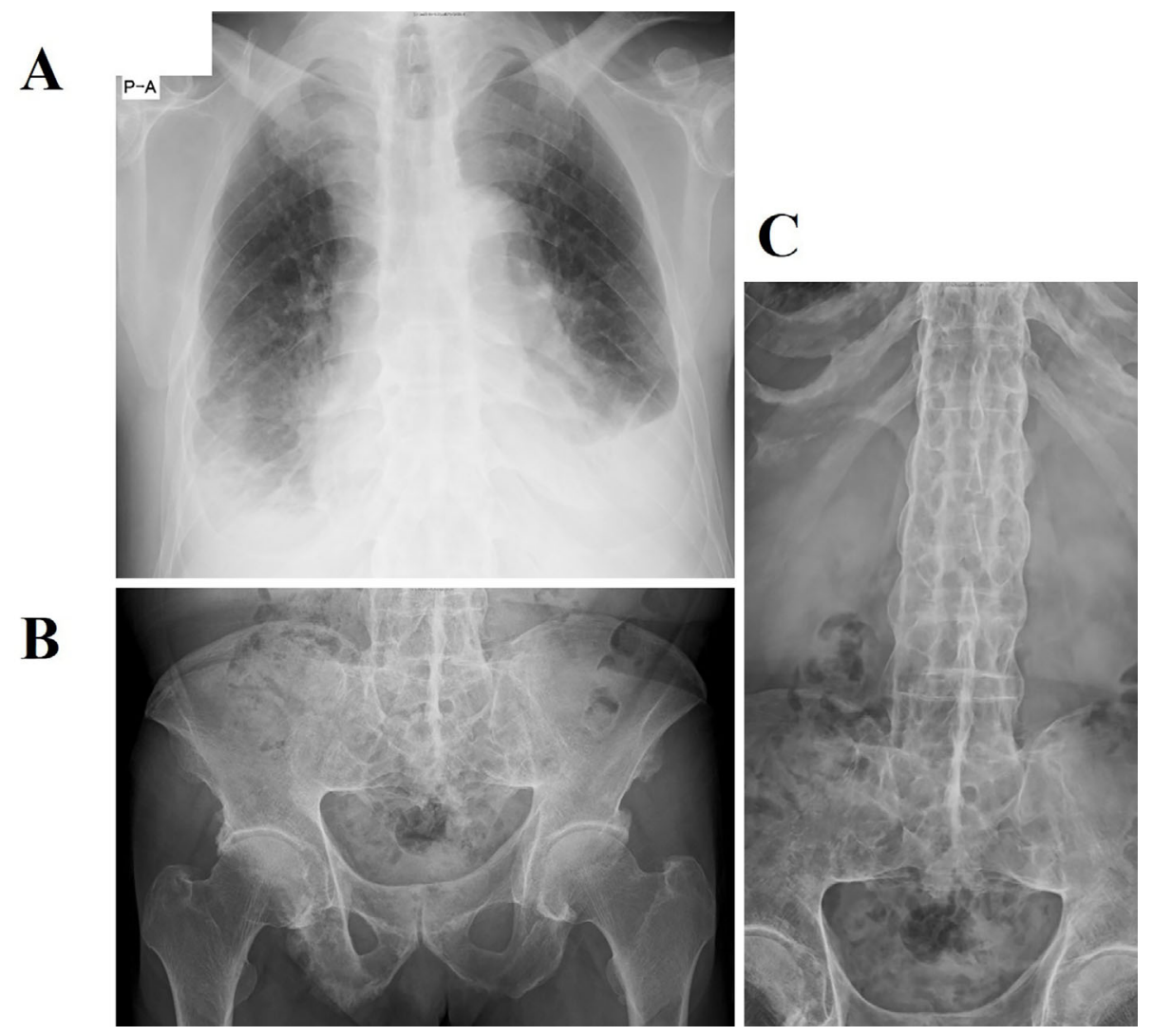

Figure 1. Chest X-ray (A), pelvic X-ray (B), and lumbar spine X-ray (C). Chest X-ray (A) showed bilateral pleural effusion. Pelvic X-ray (B) revealed joint space narrowing, and supine X-ray (C) showed bamboo spine.

A

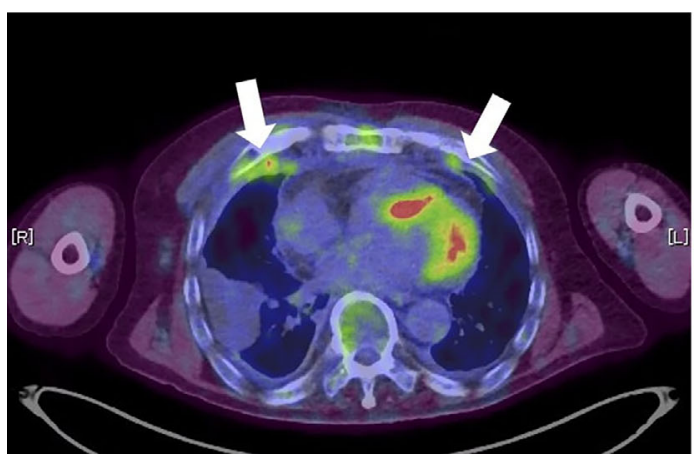

B

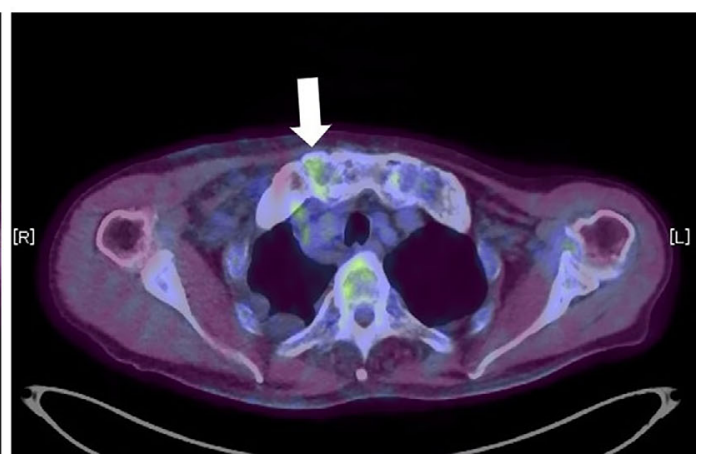

Figure 2. FDG PET/CT images: bilateral pleural fluid and pleural thickness with the uptake of FDG (A) and sternoclavicular joints with the slight uptake of FDG (B).

tern). Perinuclear and cytoplasmic antineutrophil cytoplasmic antibody were negative, as was HLA-B27.

Chest X-ray showed blunting of the costophrenic angles and bilateral pleural effusion (Fig. 1A). Pelvic X-ray revealed joint space narrowing and partial ankylosis of the sacroiliac joints (Fig. 1B). Lumbar spine X-ray showed syndesmophytes and ankylosis of the facet joints, recognized as bamboo spine (Fig. 1C). Cardiac ultrasonography showed that the left ventricular motion had a regional abnormality, but the ejection fraction was $53 \%$, and there was no valvular disease. F-18 Fluorodeoxyglucose positron emission to- mography/computed tomography (FDG PET/CT) showed bilateral pleural fluid and pleural thickness with the uptake of FDG (maximum standardized uptake value $\left[\mathrm{SUV}_{\max }\right] 5.0$ ) on both sides (Fig. 2A). Hyperplasia of sternoclavicular joints with the slight uptake of FDG $\left(\mathrm{SUV}_{\max } 3.2\right)$ was also detected (Fig. 2B), but on FDG PET/CT, there were no abnormal findings in the lungs, salivary or lacrimal glands, lymph nodes, or other major organs. Contrast magnetic resonance imaging (MRI) of the thorax revealed that the bilateral sternoclavicular joints were bony and enlarged. There was mild bone marrow edema and contrast enhancement of the right 
clavicle (Fig. 3).

The laboratory results of the pleural fluid were as follows: cell count $1,500 / \mu$ l (neutrophils $26.0 \%$, lymphocytes $68.2 \%$ ), TP $4.2 \mathrm{~g} / \mathrm{dL}, \mathrm{LDH} 101 \mathrm{U} / \mathrm{L}$, and adenosine deaminase 15.2 U/L. The pleural fluid cultures were negative, and there were no malignant cells on cytology. According to the diagnostic criteria of SAPHO syndrome proposed by Benhamou in 1988 (3), we made a diagnosis of SAPHO syndrome based on the palmoplantar pustulosis, bilateral sternal and spine osteitis, osteosclerosis of the sacroiliac joints, and suspected pleuritis associated with SAPHO syndrome.

Although infection and malignancy were considered unlikely to be the cause of the pleural effusion, we also considered malignant pleural mesothelioma, IgG4-related disease, and amyloidosis as possible differential diagnoses. On hospital day 15, a left pleural biopsy using thoracoscopy under local anesthesia was performed to examine the cause of the pleural fluid and pleural thickness. The parietal pleura was generally erythematous and hypertrophic with some white plaques. A pathological examination of the pleura re-

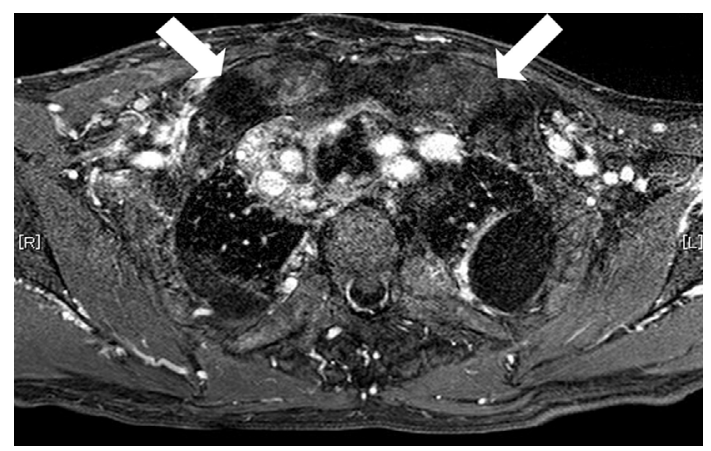

Figure 3. Contrast MRI of the thorax showed enlarged bilateral sternoclavicular joints.

A

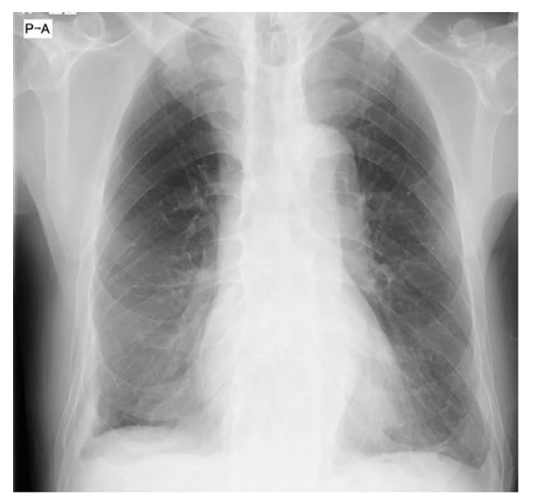

vealed nonspecific but severely inflamed fibroconnective tissue with dominant infiltration of lymphocytes (Fig. 4) and no malignancy, Congo red staining, or infiltration of plasma cells, with an $\mathrm{IgG} 4 / \mathrm{IgG}$ ratio exceeding $40 \%$. Given the result of the biopsy, we diagnosed the pleural effusion as having been caused by SAPHO syndrome.

Loxoprofen had been prescribed for his chest pain on admission, but his pleural fluid accumulation was exacerbated. Corticosteroid therapy, in the form of oral prednisolone (PSL) $30 \mathrm{mg} /$ day, was administered on hospital day 25. His respiratory symptoms gradually improved, resulting in cessation of oxygen supplementation therapy, and was accompanied by the reduction of pleural effusion (Fig. 5A). Chest CT performed 18 days after PSL initiation showed that the pleural effusion was markedly reduced compared with before the treatment and had almost disappeared (Fig. 5B). PSL was gradually tapered, and he was discharged on hospital day 49. There has been no recurrence of pleural fluid in

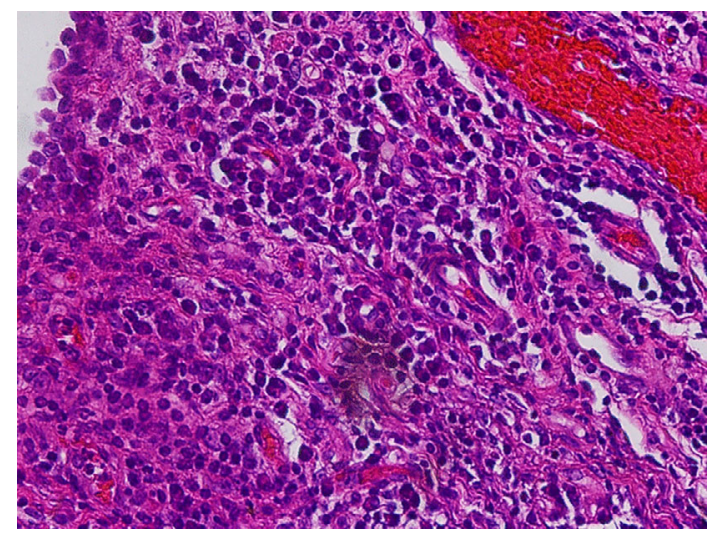

Figure 4. Thoracoscopic pleural biopsy specimen (Hematoxylin and Eosin staining $\times 400$ ).

B

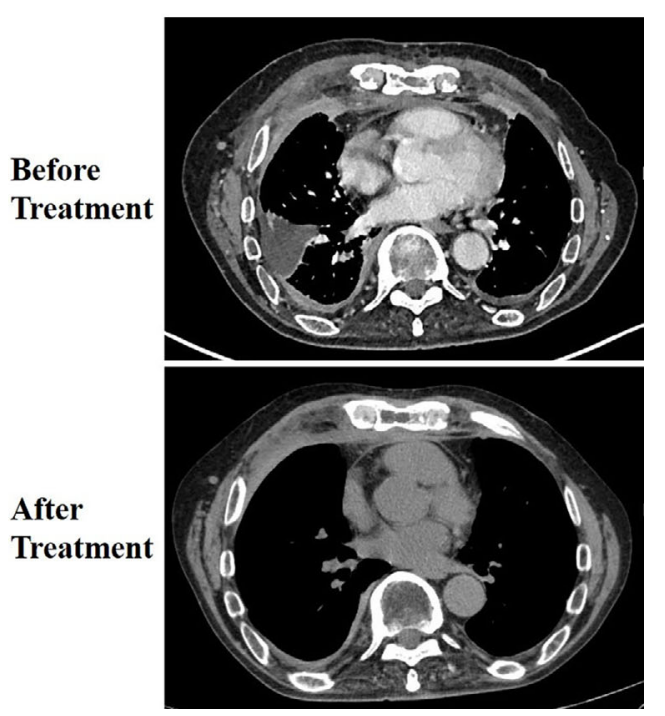

Figure 5. Chest X-ray (A) after treatment and chest CT before and after treatment (B). Chest Xray (A) demonstrated the improvement of the bilateral pleural effusion. Chest CT (B) also showed a reduction in the bilateral effusion and pleural thickening compared to before treatment. 
Table. The Reported Cases of SAPHO Syndrome with Pleural Effusion.

\begin{tabular}{|c|c|c|c|c|c|c|c|c|}
\hline Year & Reference & Gender & Age & Other symptoms & $\begin{array}{l}\text { Pleural effusion } \\
\text { unilateral } \\
\text { /bilateral }\end{array}$ & $\begin{array}{l}\text { Pleural } \\
\text { effusion } \\
\text { characteristics }\end{array}$ & Treatment & Resolution \\
\hline 1999 & 5 & Female & 16 & $\begin{array}{l}\text { Right sacroiliac joint and } \\
\text { right knee pain }\end{array}$ & Left & $\begin{array}{l}\text { Lymphocytic } \\
\text { exudate }\end{array}$ & None & $\begin{array}{l}\text { Spontaneous } \\
\text { resolution }\end{array}$ \\
\hline 2001 & 6 & Male & 61 & $\begin{array}{l}\text { Both shoulders and left hip } \\
\text { pain, stiffness of chest wall }\end{array}$ & Right & $\begin{array}{l}\text { Eosinophilic } \\
\text { exudate }\end{array}$ & Not available & $\begin{array}{l}\text { Spontaneous } \\
\text { resolution }\end{array}$ \\
\hline 2017 & 7 & Female & 66 & $\begin{array}{l}\text { Sternum, sternoclavicular, } \\
\text { acromioclavicular, and } \\
\text { sacroiliac joints pain, } \\
\text { middle thoracic and lumbar } \\
\text { vertebrae pain }\end{array}$ & Bilateral & $\begin{array}{l}\text { Neutrophilic } \\
\text { exudate }\end{array}$ & $\begin{array}{l}\text { Acetaminophen, } \\
\text { loxoprofen, } \\
\text { tramadol, } \\
\text { methotrexate }\end{array}$ & $\begin{array}{l}\text { Resolution } \\
\text { after } \\
\text { methotrexate }\end{array}$ \\
\hline \multirow[t]{2}{*}{2018} & 8 & Male & 70 & $\begin{array}{l}\text { Proximal epiphysis of both } \\
\text { clavicles and the } \\
\text { sternochondral joints pain }\end{array}$ & Right (2013) & $\begin{array}{l}\text { Lymphocytic } \\
\text { exudate }\end{array}$ & \multirow{2}{*}{$\begin{array}{l}\text { Methotrexate } \\
\text { (continued } \\
\text { before onset of } \\
\text { pleural effusion) }\end{array}$} & $\begin{array}{l}\text { Spontaneous } \\
\text { resolution }\end{array}$ \\
\hline & & & & & Left (2017) & $\begin{array}{l}\text { Lymphocytic } \\
\text { exudate }\end{array}$ & & $\begin{array}{l}\text { Spontaneous } \\
\text { resolution } \\
\text { (Contralateral } \\
\text { recurrence) }\end{array}$ \\
\hline 2021 & Present case & Male & 71 & $\begin{array}{l}\text { Sternum and both } \\
\text { sternoclavicular pain, } \\
\text { lumbar vertebrae pain }\end{array}$ & Bilateral & $\begin{array}{l}\text { Lymphocytic } \\
\text { exudate }\end{array}$ & $\begin{array}{l}\text { Loxoprofen, } \\
\text { prednisolone } \\
30 \mathrm{mg} / \text { day }\end{array}$ & $\begin{array}{l}\text { Resolution } \\
\text { after } \\
\text { corticosteroid }\end{array}$ \\
\hline
\end{tabular}

the year since PSL was initiated.

\section{Discussion}

SAPHO syndrome is a rare disease with an estimated prevalence likely less than 1 in 10,000. Most initial reports about the disease were from Japan and northwestern Europe (4). It is difficult to diagnose this disease not only because of its rarity but also because of the diverse clinical manifestations. The most widely applied diagnostic criteria of SAPHO syndrome were proposed by Benhamou in 1988, based on the presence of at least one of the following four inclusion criteria: osteoarticular manifestations of severe acne; osteoarticular manifestations of palmoplantar pustulosis; hyperostosis with or without dermatosis; and chronic recurrent multifocal osteomyelitis with or without dermatosis (3). We diagnosed the present patient based on the presence of osteoarticular manifestations of palmoplantar pustulosis and hyperostosis. Recently, SAPHO syndrome has been a concept that has been proposed to include pustulotic arthro-osteitis (PAO), acne arthritis, and chronic recurrent multifocal osteomyelitis (CRMO) $(2,3)$. From this perspective, our patient was classified as having PAO because he had bilateral hyperplasia of the sternoclavicular joints and bamboo spine with a history of pustulosis palmaris et plantaris.

Our case was an uncommon one because of the presence of pleuritis, which was recognized from findings such as bilateral exudative pleural effusion and thickening. The etiology and clinical characteristics of SAPHO syndrome occurring in pleuritis remain unclear (4). To clarify the clinical features of pleuritis with SAPHO syndrome, we searched for cases similar to our own patient in PubMed/MEDLINE and identified four (Table) (5-8). Interestingly, these cases varied in age but showed little difference in gender. All of the cases had sternum and sternoclavicular pain, suggesting that thoracic inflammation might be related to pleural involvement of SAPHO syndrome. The pleural effusion could be either unilateral or bilateral, and the characteristics of the pleural effusion differed among the cases, so no common features could be detected with regard to pleural involvement in SAPHO syndrome. Furthermore, it was difficult to detect any marked differences in clinical characteristics between those with and without pleural involvement among cases with thoracic inflammation in SAPHO syndrome. Although contiguous chronic sternal inflammation is a possible mechanism, it is very important to exclude other reasons for the occurrence of pleuritis because of the difficulty of diagnosing SAPHO syndrome related to pleural involvement based on the clinical features alone (6). Hasegawa et al. reported a patient with pleuritis and undiagnosed SAPHO syndrome, similar to our own case, and pointed out that consideration should be given to the possibility of SAPHO syndrome when encountering a case with anterior chest pain and pleural effusion. Furthermore, they noted that imaging studies, such as X-ray and CT, were needed to investigate the presence of osteosclerosis and hyperostosis of the anterior chest wall (7). However, frequent causes of pleuritis include infectious diseases, malignancy, and autoimmune diseases, so caution should be exercised, especially in undiagnosed cases of SAPHO syndrome.

We ruled out the abovementioned differential diagnoses using microbiology, cytology, laboratory data, and imaging; FDG PET/CT was particularly helpful in our case. Interestingly, FDG PET/CT also revealed not only the uptake of FDG in hypertrophic pleura and sternoclavicular joints but also the location of these lesions in close proximity. Previous reports have suggested the usefulness of FDG PET/CT in diagnosing SAPHO syndrome (9). Our observations also raised the possibility that FDG PET/CT might be beneficial for understanding the etiology of pleuritis in SAPHO syndrome. A pleural biopsy was performed in our case, demon- 
strating nonspecific but severely inflamed fibroconnective tissue with dominant infiltration of lymphocytes; we were thus able to concretely exclude other possible causes of pleuritis. As in our patient, one other case report described how a biopsy specimen of the right pleura revealed nonspecific chronic inflammation (8). Collectively, our case indicates the importance of FDG PET/CT and pathological evaluations for diagnosing pleuritis involved with SAPHO syndrome.

Anti-inflammatory therapy using oral nonsteroidal antiinflammatory drugs (NSAIDs) is the first-line therapy for SAPHO syndrome. Corticosteroid therapy, which is common for patients who do not respond to NSAIDs and Disease modified anti rheumatic drugs (DMARDs), such as methotrexate and sulfasalazine, is used to control peripheral synovitis (10). Tumor necrosis factor (TNF) inhibitors may also be used in patients with refractory disease (11). Regarding cases with pleuritis, the clinical course and treatment history differed among cases (Table). Spontaneous disappearance of pleural effusion without treatment was reported in one case (8), while the pleural effusion was ameliorated by treatment with methotrexate in a case whose clinical manifestations were similar to those in our patient (7). In our patient, loxoprofen administration did not improve the pleural effusion and was eventually discontinued because of elevated liver enzymes. Oral PSL was administered because methotrexate was incompatible with the presence of pleural fluid. After the initiation of this corticosteroid therapy, the pleural effusion diminished. About half of patients with SAPHO syndrome have a chronic course characterized by fluctuating intermittent periods of exacerbation and short improvement (12). After one year of follow-up and gradual tapering of corticosteroid treatment, our patient showed no recurrence of pleural effusions. The present and previous findings suggest that oral corticosteroid therapy and immunosuppressive drugs, such as methotrexate, are effective for improving pleuritis in cases of SAPHO syndrome, especially those without spontaneous improvement.

Several limitations associated with the present study warrant mention. First, there is a possibility that the pleural effusion was due not only to SAPHO syndrome but also the involvement of some other disease. The effect of the corticosteroid therapy could thus not be evaluated properly, as corticosteroids are used to treat many diseases, such as rheumatoid arthritis and other autoimmune diseases. Second, thus far, we have only reported the one-year follow-up of our case, and it is possible that pleural effusion might recur in the future. Morán-Álvarez et al., for example, reported a case with multiple recurrent episodes of pleural effusion (8). Therefore, for our patient, long-term observation to detect pleural effusion is needed.

In conclusion, we herein report a case of anterior chest wall osteitis possibly associated with pleuritis that showed non-specific but severe inflammation on a pleural biopsy. Our patient with SAPHO syndrome-associated pleural effusion was successfully treated with corticosteroids. Even though pleural effusion is a rare manifestation of SAPHO syndrome, SAPHO syndrome should be considered when encountering cases of anterior chest pain and pleural fluid.

The authors state that they have no Conflict of Interest (COI).

\section{Acknowledgement}

We thank Thomas Mayers of the Medical English Communications Center, University of Tsukuba, for his critical reading of the manuscript.

\section{Disclosure}

The authors state that they have no conflicts of interest to disclose.

\section{Ethical approval}

Informed consent was obtained to publish this case report.

\section{References}

1. Chamot AM, Benhamou CL, Kahn MF, Beraneck L, Kaplan G, Prost A. [Acne-pustulosis-hyperostosis-osteitis syndrome. Results of a national survey. 85 cases]. Rev Rhum Mal Osteoartic 54: 187-196, 1987.

2. Furer V, Kishimoto M, Shigeyoshi T, et al. The Diagnosis and Treatment of Adult Patients with SAPHO Syndrome: Controversies Revealed in a Multidisciplinary International Survey of Physicians. Rheumatol Ther 7: 883-891, 2020.

3. Liu S, Tang M, Cao Y, Li C, et al. Synovitis, acne, pustulosis, hyperostosis, and osteitis syndrome: review and update. Ther Adv Musculoskel Dis 12: 1-14, 2020.

4. Magrey M, Khan MA. New insights into synovitis, acne, pustulosis, hyperostosis, and osteitis (SAPHO) syndrome. Curr Rheumatol Rep 11: 329-333, 2009.

5. Dumolard A, Gaudin P, Juvin R, et al. SAPHO syndrome or psoriatic arthritis? A familial case study. Rheumatology 38: 463-467, 1999.

6. Fernandez-Campillo J, Garcia-Pachon E. Pleural effusion associated with the SAPHO syndrome. Chest 120: 1752, 2001.

7. Hasegawa S, Yabe H, Kaneko N, et al. Synovitis-acne-pustulosishyperostosis-osteitis (SAPHO) syndrome with significant bilateral pleural effusions. Int Med 56: 2779-2783, 2017.

8. Morán-Álvarez P, Bachiller-Corral J, Morell-Hita J, et al. Pleural effusion: An uncommon manifestation of SAPHO syndrome? Int $\mathrm{J}$ Rheum Dis 23: 599-601, 2020.

9. Sun X, Li C, Cao Y, et al. F-18 FDG PET/CT in 26 patients with SAPHO syndrome: A new vision of clinical and bone scintigraphy correlation. J Orthop Sun Res 13: 1-9, 2018.

10. Li C, Zuo Y, Wu N, et al. Synovitis, acne, pustulosis, hyperostosis and osteitis syndrome: A single centre study of a cohort of 164 patients. Rheumatology 55: 1023-1030, 2016.

11. Witt M, Meier J, Hammitzsch A, et al. Disease burden, disease manifestations and current treatment regimen of the SAPHO syndrome in Germany: Results from a nationwide patient survey. Semin arthritis rheum 43: 745-750, 2014.

12. Colina M, Govoni $M$, Orzincolo $C$, et al. Clinical and radiologic evolution of synovitis, acne, pustulosis, hyperostosis, and osteitis syndrome: A single center study of a cohort of 71 subjects. Arthritis Rheum 61: 813-821, 2009.

The Internal Medicine is an Open Access journal distributed under the Creative Commons Attribution-NonCommercial-NoDerivatives 4.0 International License. To view the details of this license, please visit (https://creativecommons.org/licenses/ 
by-nc-nd/4.0/)

(C) The Japanese Society of Internal Medicine Intern Med Advance Publication 